\title{
Óleo de soja e própolis na alimentação de cabras leiteiras: consumo de matéria seca e de nutrientes e parâmetros de fermentação ruminal ${ }^{1}$
}

\section{Rogério de Paula Lana ${ }^{2}$, Maíra Machado Leal Camardelli ${ }^{3}$, Marcelo Teixeira Rodrigues ${ }^{2}$, Eduardo da Costa Eifert ${ }^{4}$, Marcus Vinícius Morais de Oliveira ${ }^{5}$, Deolindo Stradiotti Júnior 6 , Juliana Silva de Oliveira ${ }^{7}$}

\author{
1 Parte da tese de Mestrado da segunda autora. Pesquisa financiada pelo CNPq - processo: 477530/01-0. \\ 2 DZO/UFV - CEP: 36571-000 - Viçosa-MG. Bolsista do CNPq. \\ ${ }^{3}$ Mestre em Zootecnia. \\ 4 Embrapa CNPAF - Santo Antônio de Goiás-GO \\ 5 UEMS - Aquidauana-MS. \\ 6 UFES - Alegre-ES. \\ ${ }^{7}$ Doutoranda em Zootecnia - UFV - CEP: 36571-000 - Viçosa-MG
}

RESUMO - Objetivou-se avaliar a inclusão de níveis crescentes de óleo de soja $(0 ; 1,5 ; 3,0 ; 4,5 ; 6,0$; e 7,5\% da MS), extrato etanólico de própolis $(0 ; 1,0 ; 2,0 ; 4,0 ; 8,0$ e $12,0 \mathrm{~mL} / \mathrm{animal} / \mathrm{dia}, 50 \%$ p/v de própolis moída em solução alcoólica a $70 \%$ em água) e própolis bruta moída $(0 ; 0,5 ; 1,0 ; 2,0 ; 4,0$ e $6,0 \mathrm{~g} / \mathrm{animal} / \mathrm{dia})$ na alimentação de cabras leiteiras. Avaliaram-se o consumo de MS e de nutrientes e alguns parâmetros de fermentação ruminal, como $\mathrm{pH}$, amônia $\left(\mathrm{NH}_{3}\right)$, ácidos graxos voláteis (AGV) e atividade específica de produção de amônia (AEPA) pela microbiota ruminal. Foram utilizadas seis cabras Alpinas fistuladas no rúmen, em seis períodos experimentais. As dietas foram compostas de $67 \%$ de silagem de milho e $33 \%$ de concentrado à base de fubá de milho e farelo de soja. Os animais foram submetidos ao tratamento controle e, em seguida, a cinco níveis crescentes de óleo de soja, extrato etanólico de própolis e própolis bruta moída utilizando-se dois animais para cada produto testado, em seis períodos experimentais. Não houve efeito de níveis de óleo de soja, extrato etanólico de própolis e própolis bruta moída sobre o consumo de MS e de nutrientes e sobre os parâmetros ruminais estudados. Sugere-se, no entanto, a realização de mais pesquisas com a adição de própolis na alimentação de ruminantes, pois existem efeitos antimicrobianos comprovados in vitro e evidências de que seu fornecimento a esses animais reduz a relação acetato:propionato e a concentração de butirato no rúmen.

Palavras-chave: ácidos graxos voláteis, amônia, caprinos, pH

\section{Soybean oil and propolis in the diets of dairy goats: intake of nutrients and ruminal metabolism}

ABSTRACT - The objective of this trial was to evaluate the increasing levels of soybean oil $(0,1.5,3.0,4.5,6.0$, and $7.5 \%$ of diet dry matter), ethanolic extract of propolis $(0,1.0,2.0,4.0,8.0$, and $12.0 \mathrm{~mL} / \mathrm{animal} / \mathrm{day})$ and ground crude propolis $(0,0.5,1.0,2.0,4.0$, and $6.0 \mathrm{~g} / \mathrm{animal} / \mathrm{day})$ on intake and ruminal metabolism ( $\mathrm{pH}$, ammonia $\mathrm{N}$, VFA, and specific activity of ammonia production) in dairy goats. Six ruminally fistulated female Alpine goats were used in a completely randomized design with six experimental periods and two animals per treatment. Diets contained $67 \%$ of corn silage and $33 \%$ of concentrate composed by ground corn and soybean meal. There was no effect of the increasing levels of soybean oil, ethanolic extract of propolis and ground crude propolis on the measured variables. More research with propolis is needed because of its anti-microbial effects in vitro and its effects on reducing the acetate:propionate ratio and the butyrate concentration in the rumen.

Key Words: ammonia, goat, $\mathrm{pH}$, volatile fatty acids

\section{Introdução}

O uso de lipídios na alimentação de animais ruminantes é realizado principalmente para aumentar a densidade energética das dietas, pois o valor energético desses lipídios é 2,25 vezes maior que o dos carboidratos (Reddy et al., 1994; Simas, 1998).
A presença de lipídios insaturados em rações pode proporcionar efeitos desejáveis, como inibição da produção de metano e amônia no rúmen e aumento na eficiência de síntese microbiana (Van Nevel \& Demeyer, 1988; Harfoot $\&$ Hazlewood, 1997). Por outro lado, pode apresentar efeitos indesejáveis, como redução na digestibilidade de MS, MO e celulose (Schneider \& Flatt, 1975; Schauff et al., 1992). 
A redução da concentração de $\mathrm{NH}_{3}$ ruminal em animais com a inclusão de óleo vegetal na dieta é provocada pelo efeito sobre os protozoários e a redução da população de bactérias desaminadoras (Van Nevel \& Demeyer, 1988). A mudança da população microbiana ruminal com a utilização de lipídios foi constatada também por Lana \& Russell (1996), que notaram que o óleo de milho, assim como os ionóforos monensina e lasalocida, aumentou a resistência das bactérias ruminais à perda do potássio intracelular quando as bactérias foram submetidas in vitro a níveis crescentes de ionóforos. Essa característica é associada à mudança da população microbiana de gram-positiva para gram-negativa.

Lipídios insaturados estimulam as bactérias ruminais produtoras de propionato, causando, conseqüentemente, decréscimo na relação acetato:propionato e na produção de metano (Richardson et al., 1984; Chalupa et al., 1986). $\mathrm{O}$ aumento da proporção molar de propionato é provocado pelo acréscimo da produção e pela concomitante redução da produção de acetato e butirato (Van Nevel \& Demeyer, 1988).

Christensen et al. (1994) não observaram efeito da adição de óleo de milho e sebo bovino em dietas sobre o pH ruminal, mas as concentrações de amônia foram reduzidas e as de isovalerato também tenderam a diminuir. Vargas et al. (2002) verificaram aumento do $\mathrm{pH}$ pela fonte de lipídio, especialmente grão de soja, e tendência à redução na produção de amônia e isovalerato e concluíram que o aumento do $\mathrm{pH}$ provavelmente resultou da queda no consumo de MS e da menor fermentação ruminal, que proporciona menor acúmulo de ácidos graxos voláteis, principal fator de redução do $\mathrm{pH}$.

De acordo com Park et al. (1998), a própolis é uma resina de coloração e consistência variada coletada por abelhas em diversas partes de plantas de diferentes espécies; seus efeitos terapêuticos têm sido atribuídos aos diversos compostos fenólicos que a compõem. A atividade antimicrobiana da própolis ocorre pela inibição das bactérias gram-positivas (Park et al., 2000). Foi constatada inibição do crescimento de bactérias Gram-positivas, responsáveis pela incidência de mastite em bovinos leiteiros (Pinto, 2001). Entretanto, não há relatos da aplicabilidade da própolis como aditivo nutricional para ruminantes e de seus efeitos sobre a microbiota ruminal.

Este experimento foi realizado com o objetivo de avaliar os efeitos da adição de óleo de soja, extrato etanólico de própolis e própolis bruta moída na alimentação de cabras leiteiras sobre o consumo de matéria seca e de nutrientes e os parâmetros de fermentação ruminal.

\section{Material e Métodos}

O ensaio foi conduzido no Setor de Caprinocultura e as análises bromatológicas, no Laboratório de Nutrição Animal do Departamento de Zootecnia. As análises de amônia $\left(\mathrm{NH}_{3}\right)$ ruminal e da atividade específica de produção de amônia (AEPA) pela microbiota ruminal foram realizadas no Laboratório de Anaeróbios do Departamento de Microbiologia e as de ácidos graxos voláteis (AGV) no líquido ruminal, no Laboratório de Cromatografia do Departamento de Química, todos da Universidade Federal de Viçosa - MG.

Foram utilizadas seis cabras multíparas, secas, fistuladas no rúmen $(70 \mathrm{~kg}$ de $\mathrm{PV})$. Os animais foram alimentados, durante os seis períodos experimentais, com a mesma dieta, composta de $67 \%$ de silagem de milho e $33 \%$ de concentrado à base de fubá de milho e farelo de soja (Tabela 1). A composição bromatológica da silagem de milho, do concentrado e da dieta total encontra-se na Tabela 2.

Tabela 1 - Composição percentual da dieta utilizada no experimento

Table 1 - Ingredient composition of the experimental diet

\begin{tabular}{lc}
\hline $\begin{array}{l}\text { Alimento } \\
\text { Feed }\end{array}$ & $\begin{array}{r}\text { Proporção (\% MS } \\
\text { Proportion (\%DM }\end{array}$ \\
\hline Silagem de milho (Corn silage) & 67,2 \\
Fubá de milho (Ground corn) & 15,5 \\
Farelo de soja (Soybean meal) & 12,4 \\
Farelo de trigo (Wheat bran) & 1,64 \\
Farelo de algodão (Cottonseed meal) & 1,64 \\
Uréia + sulfato de $\mathrm{NH}_{3}$ (Urea + ammoniun sulphate) & 0,33 \\
Núcleo mineral (Mineral mix) & 1,31 \\
NDT (TDN) & 69,32 \\
PB (CP) & 15,11 \\
EE & 2,76 \\
\hline
\end{tabular}

1 Valores calculados com base no banco de dados de composição de alimentos do Sistema Viçosa de Formulação de Rações (Lana, 2000).

1 Calculated values based on feed composition from the Viçosa System of Ration Formulation (Lana, 2000).

Tabela 2 - Composição bromatológica (\%MS) da silagem de milho, do concentrado e da dieta tota

Table 2 - Chemical composition of corn silage, concentrate and total die

\begin{tabular}{lccc}
\hline & $\begin{array}{c}\text { Silagem de milho } \\
\text { Corn silage }\end{array}$ & $\begin{array}{c}\text { Concentrado } \\
\text { Concentrate }\end{array}$ & $\begin{array}{c}\text { Dieta total } \\
\text { Total diet }\end{array}$ \\
\hline MS (DM) & 28,09 & 87,17 & 47,58 \\
MO (OM) & 94,27 & 91,87 & 93,47 \\
PB $(C P)$ & 7,13 & 17,62 & 10,59 \\
EE & 2,61 & 2,32 & 2,51 \\
FDN $(N D F)$ & 45,81 & 10,71 & 34,23 \\
CNF $(N F C)$ & 43,24 & 73,06 & 53,08 \\
\hline
\end{tabular}

${ }^{1}$ FDN corrigida para cinzas e proteína.

${ }^{1}$ NDF corrected for ash and protein. 
Tabela 3 - Níveis de inclusão de óleo de soja e própolis na dieta Table 3 - Increasing levels of soybean oil and propolis in the diet

$\begin{array}{ccc}\begin{array}{c}\text { Óleo de soja } \\ \text { (\% da MS) }\end{array} & \begin{array}{c}\text { Extrato etanólico de } \\ \text { própolis }\end{array} & \begin{array}{c}\text { Própolis bruta } \\ \text { moída (g/animal/dia) } \\ \left(\mathrm{mL} / \text { animal/dia) }{ }^{1}\right.\end{array} \\ \begin{array}{ccc}\text { Soybean oil } \\ (\% \text { of DM) }\end{array} & \begin{array}{c}\text { Ethanolic extract } \\ \text { oropolis(mL/animal/day })^{1}\end{array} & \begin{array}{c}\text { Ground } \text { crude } \\ \text { propolis (g/animal/day) }\end{array}\end{array}$

\begin{tabular}{lrrr}
\hline $1^{2}$ & 0 & 0 & 0 \\
2 & 1,5 & 1,0 & 0,5 \\
3 & 3,0 & 2,0 & 1,0 \\
4 & 4,5 & 4,0 & 2,0 \\
5 & 6,0 & 8,0 & 4,0 \\
6 & 7,5 & 12,0 & 6,0 \\
\hline
\end{tabular}

${ }^{1}$ A própolis bruta $(50 \%$ p/v) foi moída em solução alcoólica a $70 \%$ em água por um período de dez dias, seguido de filtragem em papel-filtro.

2 Período 1 = controle.

$150 \% \mathrm{wt} / \mathrm{v}$ of ground crude propolis in $70 \%$ ethanolic solution

2 Period 1 = control.

O experimento consistiu da adição na dieta de níveis crescentes de óleo de soja $(0 ; 1,5 ; 3,0 ; 4,5 ; 6,0$ e $7,5 \%$ da MS da dieta), extrato etanólico de própolis $(0 ; 1,0 ; 2,0 ; 4,0 ; 8,0$ e $12,0 \mathrm{~mL} / \mathrm{animal} / \mathrm{dia})$ e própolis bruta moída $(0 ; 0,5 ; 1,0 ; 2,0$; 4,0 e 6,0 g/animal/dia), conforme apresentado na Tabela 3 , de modo que cada produto foi fornecido a duas cabras. Para obtenção do extrato da própolis, a própolis bruta $(50 \%$ p/v) foi moída em solução alcoólica a $70 \%$ em água por um período de dez dias e, em seguida, foi filtrada em papel-filtro, conforme técnica descrita por Stradiotti Jr. et al. (2004).

Foram utilizados seis períodos experimentais de sete dias (seis para adaptação a cada nível de óleo de soja, de extrato etanólico de própolis e de própolis bruta moída e um dia para coleta de líquido ruminal e de amostras do volumoso e do concentrado fornecidos). Adotou-se o aumento gradativo do nível de óleo de soja, extrato etanólico de própolis e própolis bruta moída com o avanço dos períodos experimentais, visto que não há conhecimento sobre o nível máximo tolerável (esta é a segunda pesquisa realizada como uso de própolis e a primeira na qual foram testados níveis crescentes desse produto na alimentação de ruminantes).

Os animais foram vermifugados e pesados antes do início do experimento e alojados em baias individuais para estudos de digestibilidade, providas de bebedouros automáticos e de comedouros. As dietas foram fornecidas à vontade, de modo que houvesse pelo menos $5 \%$ de sobras. Os animais foram alimentados individualmente às $8,12 \mathrm{e} 16 \mathrm{~h}$ e receberam o concentrado juntamente com o volumoso. $\mathrm{O}$ óleo de soja, o extrato etanólico de própolis e a própolis bruta moída foram divididos em três porções diárias, adicionados diretamente sobre os alimentos no cocho às 8,12 e 16 h e misturados.

Nos períodos de adaptação e de coletas, foram feitas pesagens da silagem e do concentrado oferecidos e das sobras. As sobras de cada animal foram amostradas todos os dias, sendo preparadas amostras compostas referentes a cada período experimental para determinação dos teores de MS (a $\left.105^{\circ} \mathrm{C}\right), \mathrm{MO}, \mathrm{PB}$ e EE, utilizando-se as técnicas descritas por Silva (1998), e de fibra em detergente neutro (FDNcp), segundo Van Soest et al. (1991). As análises foram realizadas ainda nas amostras do volumoso e do concentrado.

Para determinação do $\mathrm{pH}$, da concentração de amônia $\left(\mathrm{NH}_{3}\right)$ e de ácidos graxos voláteis (AGV) no líquido ruminal, as amostras foram coletadas manualmente, via fístula de rúmen, e filtradas em gaze. Para a leitura imediata do $\mathrm{pH}$ no líquido ruminal, foi utilizado potenciômetro. Os tempos de coleta foram de $0,3,6$ e 9 horas após a alimentação da manhã.

As amostras do líquido ruminal para análise das concentrações de amônia $\left(\mathrm{NH}_{3}\right)$ foram colocadas em tubos eppendorf de $1,5 \mathrm{~mL}$ e centrifugadas a $5.200 \mathrm{x}$ g por 10 minutos retirando-se o sobrenadante com uma seringa até completar outro tubo eppendorf para posterior congelamento. A concentração de amônia foi determinada pela técnica colorimétrica descrita por Chaney \& Marbach (1962).

As amostras do líquido ruminal para análise de AGV foram colocadas em tubos eppendorf de $1,5 \mathrm{~mL}$ e centrifugadas a $13.000 \mathrm{x}$ g por 20 minutos, retirando-se $500 \mu \mathrm{L}$ do sobrenadante e colocando-os em tubos vial de $2 \mathrm{~mL}$ juntamente com $500 \mu \mathrm{L}$ de ácido meta-fosfórico a $25 \%$.

As análises dos líquidos sobrenadantes foram realizadas em cromatógrafo a gás, modelo Shimadzu GC/17A, com auto-injetor Shimadzu AOC17, que, por meio de um módulo de comunicação Shimadzu CBM - 101, foi acoplado a um microcomputador Pentium 100 com o software Class GC10, versão 1.6.1.

Os AGVs foram separados em uma coluna $\mathrm{Nukol}^{\mathrm{TM}}$ capilar, de sílica fundida ( $30 \mathrm{~m}$ x 0,25 mm x 0,25 mm Film Thikness, Supelco, Inc., Bellefonte, PA). O detector utilizado foi o de ionização de chama (FID). Como gás de arraste, utilizou-se nitrogênio e, para formação de chama, foram usados hidrogênio e ar sintético. Para determinação dos padrões de AGV, utilizou-se o kit de ácidos orgânicos Supelco.

A atividade específica de produção de amônia (AEPA) foi determinada pela microbiota ruminal, em amostras coletadas 3 horas após a alimentação da manhã, como descrito anteriormente, acondicionadas em frascos de vidro com tampa e mantidas em sala de incubação. As amostras ficaram em repouso durante 40 minutos para decantação e separação de partículas alimentares. Foram transferidos (em duplicata) $9 \mathrm{~mL}$ do líquido ruminal para tubos de incubação, que foram preenchidos com $\mathrm{CO}_{2} \mathrm{e}$ vedados com rolha de borracha. No tempo zero (0), $1 \mathrm{~mL}$ de solução 
anaeróbica de Trypticase (BBL Microbiology Systems, Cockeysville, MD) foi adicionado aos tubos $(15 \mathrm{~g} / \mathrm{L}$ de concentração final), que foram incubados a $39^{\circ} \mathrm{C}$ por 4 horas. $\mathrm{O}$ meio foi coletado $(1,5 \mathrm{~mL})$ imediatamente antes e após a incubação e armazenados a $-15^{\circ} \mathrm{C}$ para posterior estimação de amônia pela técnica colorimétrica proposta por Chaney \& Marbach (1962).

A concentração de proteína bacteriana foi determinada pela técnica colorimétrica descrita por Lowry et al. (1951). Olíquido sobrenadante $(1,5 \mathrm{~mL})$ foi centrifugado a $13.000 \mathrm{x} g$, por cinco minutos, sendo realizadas sucessivas ressuspensões e centrifugações do pellet bacteriano em solução de $\mathrm{NaCl}$ a $0,9 \%(\mathrm{p} / \mathrm{v})$, seguidas do restabelecimento do volume final com solução fisiológica para $1,5 \mathrm{~mL}$ e do armazenamento em tubos eppendorf a $-15^{\circ} \mathrm{C}$ para posterior análise.

A AEPA foi determinada conforme Lana \& Russell (1997) utilizando-se a seguinte fórmula: $\mathrm{AEPA}=\left(\triangle \mathrm{NH}_{3} \times 1.000 .000\right) /$ proteína microbiana/min, em que AEPA $=\mathrm{nmol} \mathrm{NH}_{3} / \mathrm{mg}$ proteína microbiana/minuto; $\triangle \mathrm{NH}_{3}=$ concentração final inicial de amônia $(\mathrm{mM})$; proteína microbiana = concentração inicial (mg/L); e min = tempo de incubação (minutos).

Foram realizadas análises de regressão para determinação do efeito dos níveis (seis) de óleo de soja (OLS), extrato etanólico de própolis (EEP) e própolis bruta moída (PBM) sobre os parâmetros avaliados, com duas repetições (cabras) por produto testado, totalizando 36 unidades experimentais. Foram feitos ainda testes de média, em um delineamento inteiramente casualizado, com quatro tratamentos (controle, OLS, EEP e PBM) e duas repetições, totalizando oito unidades experimentais. Cada unidade experimental do tratamento controle consistiu do cálculo da média dos dados de três cabras no primeiro período experimental, em que não houve inclusão de aditivos alimentares. As outras seis unidades experimentais utilizadas nos testes de médias (duas cabras em cada um dos produtos testados: OLS, EEP e PBM) consistiram da obtenção, por cabra, das médias provenientes dos cinco níveis de cada produto testado, excluindo o nível zero (0). Foram analisados os consumos de MS, MO, PB, EE, FDN e CNF, os teores de ácidos graxos voláteis ruminais (AGV) e de amônia ruminal $\left(\mathrm{NH}_{3}\right)$, o $\mathrm{pH}$ ruminal e a atividade específica de produção de amônia (AEPA). As análises estatísticas foram feitas utilizando-se os procedimentos de regressão e GLM do MINITAB (Ryan \& Joiner, 1994) a $5 \%$ de probabilidade.

\section{Resultados e Discussão}

Não houve efeito de aditivo alimentar (óleo de soja, extrato etanólico de própolis e própolis bruta moída) e interação aditivo $\times$ nível de inclusão sobre os consumos de $\mathrm{MS}, \mathrm{MO}, \mathrm{PB}, \mathrm{FDN} \mathrm{e} \mathrm{CNF}$, as concentrações de $\mathrm{AGV}_{\text {e } \mathrm{NH}_{3}}$ ruminais, o $\mathrm{pH}$ e a atividade específica de produção de amônia (AEPA) pela microbiota ruminal.

Como não houve efeito de nível de aditivo alimentar, foram aplicados os testes de média conforme descrito anteriormente. As características relacionadas ao consumo não foram afetadas $(\mathrm{P}>0,05)$ pelos tratamentos, exceto $\mathrm{o}$ consumo de $\mathrm{EE}(\mathrm{P}<0,01)$ no tratamento contendo óleo de soja (Tabela 4), que aumentou como resultado do efeito direto do uso de óleo de soja.

Os valores do consumo diário de MS observado foram inferiores aos obtidos por Gonçalves et al. (2001), de 2,33 a

Tabela 4 - Consumos de MS e nutrientes de acordo com os níveis de própolis o óleo de soja na dieta Table 4 - DM and nutrient intakes according to increasing levels of soybean oil and propolis in the diet

\begin{tabular}{|c|c|c|c|c|c|c|}
\hline \multirow[t]{2}{*}{$\begin{array}{l}\text { Consumo } \\
\text { Intake }\end{array}$} & \multicolumn{4}{|c|}{$\begin{array}{c}\text { Tratamento } \\
\text { Treatment }\end{array}$} & \multirow[t]{2}{*}{$\begin{array}{l}\mathrm{EP} \\
S E\end{array}$} & \multirow[t]{2}{*}{$\begin{array}{c}\text { Probabilidade } \\
\text { Probability }\end{array}$} \\
\hline & $\begin{array}{l}\mathrm{CON} \\
\mathrm{CON}\end{array}$ & $\begin{array}{l}\text { OLS } \\
S B O\end{array}$ & $\begin{array}{l}\mathrm{EEP} \\
E E P\end{array}$ & $\begin{array}{c}\mathrm{PBM} \\
G C P\end{array}$ & & \\
\hline MS (kg/animal/dia) (DM, kg/animal/day) & 1,30 & 1,23 & 1,38 & 1,32 & 0,308 & 0,99 \\
\hline $\mathrm{MS}(\% \mathrm{PV})(D M, \% B W)$ & 1,97 & 1,70 & 1,88 & 1,88 & 0,271 & 0,91 \\
\hline $\operatorname{MS}\left(\mathrm{g} / \mathrm{kg} \mathrm{PV} V^{0,75}\right)\left(D M, g / k g B W^{0.75}\right)$ & 56,30 & 49,59 & 54,94 & 54,45 & 9,055 & 0,95 \\
\hline MO (kg/animal/dia) (OM, kg/animal/day) & 1,23 & 1,15 & 1,29 & 1,24 & 0,290 & 0,99 \\
\hline PB (kg/animal/dia) (CP, kg/animal/day) & 0,141 & 0,131 & 0,145 & 0,137 & 0,031 & 0,99 \\
\hline $\mathrm{EE}(\mathrm{kg} / \mathrm{animal} / \mathrm{dia})$ (EE, $\mathrm{kg} /$ animal/day) & 0,033 & 0,079 & 0,035 & 0,033 & 0,007 & 0,001 \\
\hline FDN (kg/animal/dia) (NDF, kg/animal/day) & 0,430 & 0,417 & 0,486 & 0,458 & 0,110 & 0,97 \\
\hline $\mathrm{CNF}$ (kg/animal/dia) (NFC, $\mathrm{kg} /$ animal/day $)$ & 0,743 & 0,688 & 0,764 & 0,730 & 0,166 & 0,99 \\
\hline
\end{tabular}

${ }^{1} \mathrm{CON}=$ controle OLS = óleo de soja; EEP = extrato etanólico de própolis; $\mathrm{PBM}=$ própolis bruta moída

${ }_{1} C O N=$ control; $S B O=$ soybean oil; $E E P=$ ethanolic extract of propolis; $G C P=$ ground crude propolis. 
2,35 kg para cabras não-lactantes recebendo 20 e $40 \%$ de concentrado, respectivamente, semelhante aos valores de consumo de FDN, que foram de 1,34 e 1,01 kg.

Não houve efeito de aditivo nem da interação aditivo $\times$ tempo sobre o pH e a concentração de amônia ruminal. Entretanto, quando se utilizaram valores médios de todos os tratamentos nos tempos $0,3,6 \mathrm{e} 9$ horas, a concentração de amônia aumentou e o pH diminuiu em função do tempo de coleta de líquido ruminal (Figura 1). Desse modo, não houve estabilidade das condições ruminais com o fornecimento da alimentação três vezes ao dia nos horários de 8 , 12 e 16 horas.

Os valores de $\mathrm{pH}$ de 6,6 a 5,6 no decorrer de 9 horas após a alimentação, para animais que receberam $33 \%$ de concentrado, foram inferiores aos observados por Gonçalves et al. (2001), que, em experimento com cabras leiteiras recebendo dietas compostas por diferentes relações volumoso:concentrado, observaram $\mathrm{pH}$ de 6,5 a 6,9 ao longo de 24 horas nos animais que receberam 40 e $20 \%$ de concentrado, respectivamente.

O pH ruminal médio observado foi de 6,2 e manteve-se, na maioria do tempo, acima de 5,9 (Figura 1). Segundo Russell \& Dombrowski (1980), o crescimento das principais bactérias celulolíticas é comprometido em $\mathrm{pH}$ em torno de 6,0-6,1, sendo totalmente inibido em valores abaixo de 5,9.

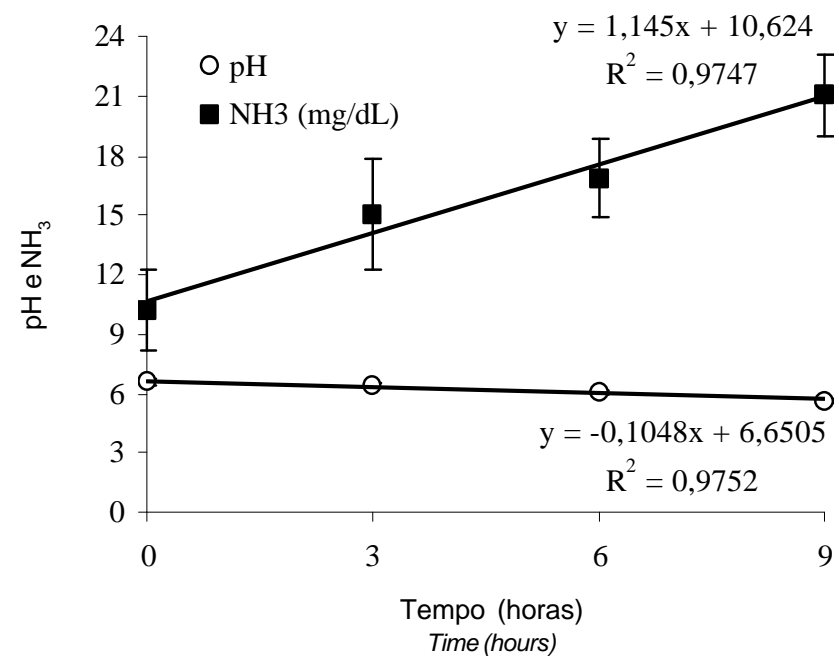

Figura 1 - Valores de $\mathrm{pH}$ e concentração de $\mathrm{NH}_{3}$ ruminal em diferentes tempos de coleta de líquido ruminal.

Figure 1 - Ruminal $\mathrm{pH}$ and ruminal $\mathrm{NH}_{3}$ concentration according to the time of collection of ruminal fluid.
A concentração média de amônia ruminal foi de $15,77 \mathrm{mg} / \mathrm{dL}$ e o valor mínimo observado foi de $10,6 \mathrm{mg} / \mathrm{dL}$ (Figura 1). Embora Mehrez \& Ørskov (1976) tenham observado que a concentração mínima de amônia deve ser de $23 \mathrm{mg} / \mathrm{dL}$ de líquido ruminal para se obter taxa máxima de crescimento microbiano, estudos in vitro (Satter \& Slyter, 1974) e in vivo (Satter \& Roffler, 1975) demonstraram que a concentração mínima de amônia deve ser de $5 \mathrm{mg} / \mathrm{dL}$ de líquido ruminal para favorecer o crescimento microbiano. Do mesmo modo, Leng \& Nolan (1984) verificaram que concentrações superiores a $5-10 \mathrm{mg} / \mathrm{dL}$ de líquido ruminal não aumentam a produção de proteína microbiana.

Não houve efeito dos tratamentos $(\mathrm{P}>0,05)$ sobre o $\mathrm{pH}$ e a amônia ruminais, a AEPA, as concentrações de acetato, propionato, butirato e ácidos graxos voláteis totais e a relação acetato:propionato (Tabela 5). Entretanto, há evidências de redução da relação acetato:propionato e da concentração de butirato no líquido ruminal pela adição de extrato etanólico de própolis.

Van Nevel \& Demeyer (1988) observaram redução da concentração de $\mathrm{NH}_{3}$ ruminal em animais que receberam óleo na dieta. Embora a adição do óleo tenha reduzido a concentração de amônia $(22,17 \%)$ em relação à dieta controle, não houve efeito estatístico atribuído ao elevado erropadrão. O efeito de lipídios na redução da concentração de $\mathrm{NH}_{3}$ ruminal pode ser atribuído à ação sobre os protozoários e à redução na população de bactérias desaminadoras (Van Nevel \& Demeyer, 1988).

Stradiotti Jr. et. al. (2004) verificaram que o extrato de própolis não afetou o consumo de MS, o pH e as concentrações de amônia e de proteína microbiana no líquido de rúmen, mas inibiu a AEPA pelos microrganismos ruminais. Os valores de AEPA apresentados por esses autores foram 11,65 e $8,10 \mathrm{nmol} / \mathrm{mg} \mathrm{PM} / \mathrm{min}$ para os tratamentos ausência e presença de extrato etanólico de própolis, respectivamente, os quais divergem dos verificados neste experimento ( 28,00 e $36,17 \mathrm{nmol} / \mathrm{mg} \mathrm{PM} / \mathrm{min}$ ). Provavelmente esses resultados decorreram da utilização de própolis de origens diferentes ou das modificações na metodologia de extração.

Lavezzo et al. (1998) observaram no fluido ruminal de ovinos concentrações médias de acetato de 37,05; 35,28 e 38,11 milimolar (mM) nos tempos 1, 3 e 6 horas após a alimentação, respectivamente, inferiores às registradas neste estudo (Tabela 5). Ítavo et al. (2000), utilizando feno de aveia e silagem de bagaço de laranja na alimentação de ovinos, verificaram concentrações médias para acetato, propionato e butirato de 40,$83 ; 12,77$ e $5,77 \mathrm{mM}$, respectivamente, próximas às descritas na Tabela 5 . 
Tabela 5 - Parâmetros de fermentação ruminal observados nos tratamentos e erro-padrão da média Table 5 - Ruminal parameters according to increasing levels of soybean oil and propolis in the diet

\begin{tabular}{|c|c|c|c|c|c|c|}
\hline & \multicolumn{4}{|c|}{$\begin{array}{c}\text { Tratamento } \\
\text { Treatment }\end{array}$} & \multirow[t]{2}{*}{$\begin{array}{l}\mathrm{EP} \\
S E\end{array}$} & \multirow[t]{2}{*}{$\begin{array}{c}\text { Probabilidade } \\
\text { Probability }\end{array}$} \\
\hline & $\begin{array}{l}\mathrm{CON} \\
\mathrm{CON}\end{array}$ & $\begin{array}{l}\text { OLS } \\
S B O\end{array}$ & $\begin{array}{l}\text { EEP } \\
E E P\end{array}$ & $\begin{array}{c}\text { PB M } \\
G C P\end{array}$ & & \\
\hline $\mathrm{pH}$ & 6,29 & 6,30 & 6,11 & 6,03 & 0,10 & 0,28 \\
\hline $\mathrm{NH}_{3}(\mathrm{mg} / \mathrm{dL})$ & 16,95 & 13,20 & 14,48 & 18,45 & 4,67 & 0,69 \\
\hline AEPA $(S A A P)^{2}$ & 28,00 & 32,31 & 36,17 & 30,25 & 5,42 & 0,75 \\
\hline Acetato $(\mathrm{mM})($ Acetate, $\mathrm{mM})$ & 44,06 & 43,17 & 48,06 & 45,36 & 4,50 & 0,88 \\
\hline Propionato (mM) (Propionate, $\mathrm{mM}$ ) & 10,75 & 12,04 & 12,39 & 9,42 & 0,91 & 0,23 \\
\hline Butirato $(\mathrm{mM})$ (Butyrate, $m M)$ & 5,05 & 2,95 & 4,15 & 3,17 & 0,58 & 0,17 \\
\hline AGV total (mM) (Total VFA, mM) & 59,86 & 58,16 & 64,6 & 57,95 & 5,43 & 0,81 \\
\hline Acetato:propionato (Acetate:propionate) & 4,32 & 3,65 & 3,84 & 4,85 & 0,29 & 0,14 \\
\hline
\end{tabular}

${ }^{1} \mathrm{CON}=$ controle; OLS = óleo de soja; EEP = extrato etanólico de própolis; $\mathrm{PBM}$ = própolis bruta moída.

$2 \mathrm{AEPA}=$ atividade específica de produção de amônia ( $\mathrm{nmol} \mathrm{NH}_{3} / \mathrm{mg}$ de proteína microbiana/minuto).

${ }_{1} C O N=$ control; $S B O=$ soybean oil; $E E P=$ ethanolic extract of propolis; $G C P=$ ground crude propolis.

$2 \mathrm{SAAP}=$ specific activity of ammonia production $\left(\mathrm{nmolNH}_{3} / \mathrm{mg}\right.$ of microbial protein/minute).

\section{Conclusões}

O uso de própolis e óleo de soja na dieta não afetou o consumo de MS e de nutrientes nem alterou os parâmetros de fermentação ruminal em cabras leiteiras. Sugere-se a realização de mais pesquisas com adição de própolis na dieta de animais ruminantes, pois existem evidências de que seu fornecimento a esses animais reduz a relação acetato:propionato e a concentração de butirato no líquido ruminal.

\section{Literatura Citada}

CHALUPA, W.; VECCHIARELLI, B.; ELSER, A.E. et al. Ruminal fermentation in vivo as influenced by long-chain fatty acids. Journal of Dairy Science, v.69, n.5, p.1293-1301, 1986.

CHANEY, A.L.; MARBACH, E.P. Modified reagents for determination of urea and ammonia. Clinical Chemistry, v.8, p.130-132, 1962.

CHRISTENSEN, R.A.; CAMERON, M.R.; CLARK, J.H. et al. Effects of amount of protein and ruminally protected amino acids in the diet of dairy cows fed supplemental fat. Journal of Dairy Science, v.77, n.6, p.1618-1629, 1994.

GONÇALVES, A.L.; LANA, R.P.; RODRIGUES, M.T. et al. Padrão nictemeral do $\mathrm{pH}$ ruminal e comportamento alimentar de cabras leiteiras alimentadas com dietas contendo diferentes relações volumoso:concentrado. Revista Brasileira de Zootecnia, v.30, n.6, p.1886-1892, 2001

HARFOOT, C.G.; HAZLEWOOD, G.P. Lipid metabolism in the rumen. In: HOBSON, P.N.; STEWART, C.S. (Eds.) The ruminal microbial ecosystem. London: Chapman \& Hall, 1997. p.382-426

ÍTAVO, L.C.V.; SANTOS, G.T.; JOBIM, C.C. et al. Avaliação da silagem de bagaço de laranja com diferentes aditivos por intermédio dos parâmetros de fermentação ruminal de ovinos e contribuição energética dos ácidos graxos voláteis. Revista Brasileira de Zootecnia, v.29, n.5, p.1491-1497, 2000.

LANA, R.P. Sistema Viçosa de formulação de rações. Viçosa, MG: Universidade Federal de Viçosa, 2000. 60p.

LANA, R.P.; RUSSELL, J.B. Use of potassium depletion to assess adaptation of ruminal bacteria to ionophores. Applied and Environmental Microbiology, v.62, n.12, p.4499-4503, 1996.
LANA, R.P.; RUSSELL, J.B. Effect of forage quality and monensin on the ruminal fermentation of fistulated cows fed continuously at a constant intake. Journal of Animal Science, v.75, p.224-229, 1997.

LANA, R.P.; RUSSELL, J.B.; van AMBURGH, M.E. The role of $\mathrm{pH}$ in regulating ruminal methane and ammonia production. Journal of Animal Science, v.76, n.8, p.2190-2196, 1998.

LAVEZZO, O.E.N.M.; LAVEZZO, W.; WECHSLER, F.S. Estágio de desenvolvimento do milho. 3. Avaliação de silagens por intermédio de parâmetros de fermentação ruminal. Revista Brasileira de Zootecnia, v.27, n.1, p.171-178, 1998.

LENG, R.A.; NOLAN, J.V. Symposium: protein nutrition of the lactating dairy cow. Nitrogen metabolism in the rumen. Journal of Dairy Science, v.67, p.1027-1089, 1984.

LOWRY, O.H.; ROSEBROUGH, N.J.; FARR, A.L. et al. Protein measurement with the Folin phenol reagent. The Journal of Biological Chemistry, v.193, p.265-275, 1951

MEHREZ, A.Z.; ØRSKOV, E.R. Rates of rumen fermentation in relation to ammonia concentration. In: PROCEEDINGS OF NUtrition SOCIETy, 35., 1976, London. Proceedings... London: Nutrition Society, v.35, n.40, 1976.

PARK, Y.K.; IKEGAKI, M.; ABREU, J.A.S. et al. Estudo da preparação dos extratos de própolis e suas aplicações. Ciência e Tecnologia de Alimentos, v.18, n.3, p.313-318, 1998.

PARK, Y.K.; IKEGAKI, M.; ALENCAR, S.M. [2000]. Classificação das própolis brasileiras a partir de suas características físicoquímicas e propriedades biológicas. Mensagem Doce, v.58. Disponível em: http:<//www.apacame.org.br/mensagemdoce/58/ artigo.htm.> Acesso em: 07/02/2003.

PINTO, M.S.; FARIA, J.E.; MESSAGE, D. et al. Efeito de extratos de própolis verde sobre bactérias patogênicas isoladas do leite de vacas com mastite. Brazilian Journal of Veterinary Research and Animal Science, v.38, n.6, p.278283, 2001 .

REDDY, P.V.; MORRIL, J.L.; NAGARAJA, T.G. Release of free fatty acids from raw or processed soybeans and subsequent effects on fiber digestibilities. Journal of Dairy Science, v.77, n.11, p.3410-3416, 1994

RICHARDSON, L.F.; RAUN, A.P.; POTTER, E.L. et al. Effect of monensin on ruminal fermentation in vitro and in vivo. Journal of Animal Science, v.58, p.194-202, 1984.

RUSSELL, J.B.; DOMBROWSKI, D.B. Effect of $\mathrm{pH}$ on the efficiency of growth by pure cultures of rumen bacteria in continuous culture. Applied and Environmental Microbiology, v.39, n.3, p.604-610, 1980.

RYAN, B.F.; JOINER, B.L. Minitab handbook. 3.ed. Belmont: Duxbury Press, 1994. 448p. 
SATTER, L.D.; ROFFLER, R.E. Relationship between ruminal ammonia and non protein nitrogen utilization by ruminants. I. Development of a model for predicting nonprotein nitrogen utilization by cattle. Journal of Dairy Science, v.58, n.12, p.1880-1888, 1975.

SATTER, L.D.; SLYTER, L.L. Effect of ammonia concentration on rumen microbial protein production "in vitro". British Journal of Nutrition, v.32, n.2, p.199-299, 1974.

SCHAUFF, D.J.; ELLIOTT, J.P.; CLARK, J.H. et al. Effects of feeding lactating dairy cows diets containing soybeans and tallow. Journal of Dairy Science, v.75, p.1923-1935, 1992.

SCHNEIDER, B.H.; FLATT, W.P. The evaluation of feeds through digestibility experiments. Athens: University of Georgia Press, 1975. 423p.

SILVA, D.J. Análise de alimentos: métodos químicos e biológicos. Viçosa, MG: Universidade Federal de Viçosa, 1998. 165p.

SIMAS, J.M.C. Como utilizar gordura em dieta de vacas leiteiras. Revista Balde Branco, ano 34, n.401, p.26-30, 1998.

STRADIOTTI JR., D.; QUEIROZ, A.C.; LANA, R.P. et al. Ação da própolis sobre a desaminação de aminoácidos e a fermentação ruminal. Revista Brasileira de Zootecnia, v.33, n.4, p.1086-1092, 2004.
Van NEVEL, C.J.; DEMEYER, D.I. Manipulation of ruminal fermentation. In: HOBSON, P.N. (Ed.) The rumen microbial ecosystem. Essex: Elsevier, 1988. p.387-443.

Van SOEST, P.J.; ROBERTSON, J.B.; LEWIS, B.A. Methods of dietary fiber, neutral detergent fiber, and nonstarch polysaccharides in relation to animal nutrition. Journal of Dairy Science, v.74, p.3583-3597, 1991.

VARGAS, L.H.; LANA, R.P.; JHAM, G.N. Adição de lipídios na ração de vacas leiteiras: parâmetros fermentativos ruminais, produção e composição do leite. Revista Brasileira de Zootecnia, v.31, n.1, p.522-529, 2002.

Recebido: 15/04/05 Aprovado: 21/08/06 